\title{
Diagnostic and prognostic role of mean platelet volume and mean platelet volume/platelet ratio in the most common soft tissue sarcomas
}

\author{
Şefik Murat Arıkan, $\mathrm{MD}^{1} \mathbb{D}$, Aliekber Yapar, $\mathrm{MD}^{2} \mathbb{D}$, İsmail Burak Atalay, $\mathrm{MD}^{2} \mathbb{D}$, Güray Toğral, $\mathrm{MD}^{2} \mathbb{1}$, \\ Aras Pervane, $\mathrm{MD}^{2} \mathbb{D}$, Bedii Şafak Güngör, $\mathrm{MD}^{2} \mathbb{D}$ \\ ${ }^{1}$ Department of Orthopedics and Traumatology, Gazi University School of Medicine, Ankara, Turkey \\ 2Department of Orthopaedics and Traumatology, Dr. Abdurrahman Yurtaslan Ankara Oncology Training and Research Hospital, Ankara, Turkey
}

Soft tissue sarcomas are relatively uncommon tumors, representing $1 \%$ of adult and 7 to $15 \%$ of pediatric malignancies. ${ }^{[1]}$ It is a heterogeneous group of tumors of mesenchymal origin that can occur anywhere in the body, with the extremities being the most common primary site, accounting for $60 \%$ of the soft tissue sarcomas. ${ }^{[2]}$ The most common extremity soft tissue sarcomas in adults are pleomorphic sarcoma and liposarcoma. ${ }^{[3,4]}$ These sarcomas are diagnosed clinically, radiologically, and histopathologically, and many factors affect prognosis. Studies on blood values for diagnostic and prognostic purposes have been increasing in recent years for sarcomas. ${ }^{[5-7]}$

Activated platelets (PLTs) are involved in cancer progression and metastases, and mean platelet

Received: September 10, 2020

Accepted: September 27, 2020

Published online: January 06, 2021

Correspondence: Güray Toğral, MD. Dr. Abdurrahman Yurtaslan Ankara Onkoloji Eğitim ve Arasstırma Hastanesi, Ortopedi ve Travmatoloji Kliniği, 06430 Yenimahalle, Ankara, Türkiye.

E-mail: dr_guray@hotmail.com

Doi: $10.5606 /$ ehc. 2021.78522

Citation: Arıkan ŞM, Yapar A, Atalay IB, Toğral G, Pervane A, Güngör BS. Diagnostic and prognostic role of mean platelet volume and mean platelet volume/platelet ratio in the most common soft tissue sarcomas. Jt Dis Relat Surg 2021;32(1):204-209.

(C2021 All right reserved by the Turkish Joint Diseases Foundation

This is an open access article under the terms of the Creative Commons Attribution-NonCommercial License, which permits use, distribution and reproduction in any medium, provided the original work is properly cited and is not used for commercial purposes (http://creativecommons.org/licenses/by-nc/4.0/).

\section{ABSTRACT}

Objectives: This study aims to investigate the diagnostic and prognostic role of mean platelet volume (MPV) and MPV/platelet (PLT) ratio in the most common soft tissue sarcomas.

Patients and methods: We retrospectively investigated 131 patients (76 males, 55 females; mean age: $51.8 \pm 17.1$; range, 18 to 87 years) with soft-tissue sarcomas between January 2011 and January 2019. Demographic features, MPV, PLT counts, mortality, and recurrence records of the patients were obtained from archives. A total of 165 healthy volunteers (101 males, 64 females; mean age $52.9 \pm 4.1$; range, 18 to 60 years) who applied to the outpatient clinic in 2019 and had routine blood control without any additional disease formed the control group.

Results: A total of 55 patients were diagnosed with liposarcoma and 76 with pleomorphic sarcoma. Of the tumors, $77.1 \%$ were located in the lower limbs. Lesions were mostly localized on the thigh $48.8 \%(n=64)$. Recurrence occurred in $28.2 \%$ of the patients. A total of $25(19.1 \%)$ patients were exitus. The mean follow-up period of the patients was $34.4 \pm 19.1$ (range, 9 to 112) months. The mean PLT value of the patient group was significantly higher than the control group. The median MPV and MPV/PLT ratio were statistically significantly lower in the patient group than in the control group. The MPV and MPV/PLT ratio were not associated with mortality and recurrence.

Conclusion: As a result, MPV and MPV/PLT ratio can be used as a diagnostic support parameter in soft tissue sarcomas, but have no prognostic value.

Keywords: Mean platelet volume, platelet count, soft tissue sarcoma.

volume (MPV) is a marker of activated PLTs. ${ }^{[8]}$ There are many publications in the literature investigating the diagnostic and prognostic role of MPV and MPV/PLT ratio in cancers. ${ }^{[9-13]}$ However, as far as we know, there is no study in the literature investigating the relationship between soft tissue sarcomas and MPV and MPV/PLT ratio. 
The relationship between PLT indices and cancers is a matter of curiosity. Therefore, in this study, we aimed to investigate the diagnostic and prognostic role of MPV and MPV/PLT ratio in the most common soft tissue sarcomas.

\section{PATIENTS AND METHODS}

We retrospectively investigated the patients with soft tissue sarcomas at Dr. Abdurrahman Yurtaslan Ankara Oncology Training and Research Hospital between January 2011 and January 2019. Demographic features, MPV, PLT counts, mortality, and recurrence records of the patients were obtained from archives. All MPV and PLT values of the patients were recorded before biopsy or any treatment (surgery, neoadjuvant radiotherapy or chemotherapy). A total of 131 patients (76 males, 55 females; mean age: $51.8 \pm 17.1$; range, 18 to 87 years) with soft-tissue sarcomas were included in this study. One hundred and sixty-five patients (101 males, 64 females; mean age: $52.9 \pm 4.1$; range, 18 to 60 years) who applied to the orthopedics outpatient clinic without infection, rheumatological and hematological diseases or any pathological findings in the test results were determined as the control group. Patients with hematological disease, infection, and autoimmune disease were excluded. The study protocol was approved by the SBU Dr. Abdurrahman Yurtaslan Ankara Oncology Training and Research Hospital Ethics Committee (decision number: 2020-09/767). A written informed consent was obtained from each patient. The study was conducted in accordance with the principles of the Declaration of Helsinki.

\section{Statistical analysis}

Statistical analysis was performed using the IBM SPSS version 22.0 software (IBM Corp., Armonk, NY, USA). Descriptive statistics were

\begin{tabular}{|c|c|c|c|c|c|}
\hline \multicolumn{6}{|c|}{$\begin{array}{c}\text { TABLE I } \\
\text { Basal demographics of malignancies }(n=131)\end{array}$} \\
\hline Characteristic & $n$ & $\%$ & Mean \pm SD & Median & Min-Max \\
\hline \multicolumn{6}{|l|}{ Pathology of malignancies } \\
\hline Liposarcoma & 55 & 42 & & & \\
\hline Pleomorphic sarcoma & 76 & 58 & & & \\
\hline \multicolumn{6}{|l|}{ Side } \\
\hline Right & 78 & 59.5 & & & \\
\hline Left & 53 & 40.5 & & & \\
\hline \multicolumn{6}{|l|}{ Extremity } \\
\hline Upper limb & 30 & 22.9 & & & \\
\hline Lower limb & 101 & 77.1 & & & \\
\hline \multicolumn{6}{|l|}{ Localization } \\
\hline Forearm & 5 & 3.8 & & & \\
\hline Elbow & 4 & 3.1 & & & \\
\hline Arm & 12 & 9.2 & & & \\
\hline Shoulder & 9 & 6.9 & & & \\
\hline Gluteal area & 4 & 3.1 & & & \\
\hline Thigh & 64 & 48.9 & & & \\
\hline Knee & 6 & 4.6 & & & \\
\hline Cruris & 24 & 18.3 & & & \\
\hline Ankle & 3 & 2.3 & & & \\
\hline \multicolumn{6}{|l|}{ Recurrence } \\
\hline Yes & 37 & 28.2 & & & \\
\hline No & 94 & 71.8 & & & \\
\hline \multicolumn{6}{|l|}{ Exitus } \\
\hline Yes & 25 & 19.1 & & & \\
\hline No & 106 & 80.9 & & & \\
\hline Follow-up time (months) & & & $34.4 \pm 19.1$ & 33 & $9-112$ \\
\hline
\end{tabular}


presented as numbers and percentages for categorical variables and mean \pm standard deviation, and median (minimum-maximum) for continuous variables. Normal distribution for continuous variables was assessed with visual (histograms and probability graphics) and analytic methods (Kolmogorov-Smirnov and Shapiro-Wilk test). For the non-normally distributed data, a Mann-Whitney $\mathrm{U}$ test was used for comparison analysis between the two independent groups, and an independentsamples t-test was used for the data that fit the normal distribution. Comparison analyses for categorical variables between independent groups were performed by a chi-square test. Diagnostic and prognostic values of pre-treatment PLT count, $\mathrm{MPV}$, and MPV/PLT ratio were assessed using receiver operating characteristic (ROC) analysis. The area under the ROC curve (AUC) results were considered excellent for AUC values between 0.9-1, good for AUC values between 0.8-0.9, fair for AUC values between 0.7-0.8, poor for AUC values between 0.6-0.7, and failed for AUC values between $0.5-0.6 .^{[1,2]}$ Results following ROC analysis including AUC and cut-off values, sensitivity and specificity of these cut-offs values, likelihood ratio, positive predictive value (PPV), and negative predictive value (NPV) were presented. Survival analyses were performed by Kaplan-Meier method. The effect of PLT count, MPV, and MPV/PLT ratio on survival was also evaluated by univariate Cox regression analysis. $\mathrm{P}<0.05$ was considered to be statistically significant. ${ }^{[14,15]}$

\section{RESULTS}

Of the 131 patients, 55 had a diagnosis of liposarcoma and 76 had a diagnosis of pleomorphic sarcoma. Of the tumors, $77.1 \%$ were located in the lower limbs. Lesions were mostly localized on the thigh $48.8 \%(\mathrm{n}=64)$. Recurrence occurred in $28.2 \%$ of the patients. Twenty-five $(19.1 \%)$ patients were exitus. The mean follow-up period of the patients was $34.4 \pm 19.1$ (range, 9 to 112) months (Table I). Age and sex distributions of the control and patient groups were similar $(\mathrm{p}=0.233, \mathrm{p}=0.577)$. The PLT value of the patient group was found to be significantly higher than the control group (278 vs. 254$)(\mathrm{p}=0.002)$ (Table II). Mean PLT volume and MPV/PLT ratio were statistically significantly lower in the patient group compared to the control group $(\mathrm{p}<0.001)$ (Table II).

The diagnostic predictivity of PLT count, MPV, and MPV/PLT ratio for soft tissue sarcoma was evaluated by ROC analysis (Figure 1). According to Table III, the highest significant AUC value was obtained for MPV (AUC=0.787) and then for MPV/PLT ratio (AUC=0.699). The AUC value obtained for PLT count was statistically significant but weak (AUC $=0.606)$. When the cut-off values obtained for all three parameters and sensitivity, specificity, positive likelihood ratio (+LHR), PPV, and NPV of these cut-off values were analyzed, it was observed that the predictability of MPV of 9.05 and below was better than the other two parameters in the diagnostic approach for the disease (sensitivity $=62.6 \%$, specificity $=78.2 \%, \quad+\mathrm{LHR}=2.57$, $\mathrm{PPV}=69.5 \%$, and $\mathrm{NPV}=72.5 \%$ ).

The predictability of PLT count, MPV, and MPV/PLT ratio for mortality and recurrence was evaluated by ROC analysis, and the statistical significance of AUC values obtained from ROC analysis were presented in Table IV. It was observed that all the three parameters were not statistically significant, and there was no significant AUC value above 0.7 (Table IV). The mean survival in this study was $87.9 \pm 4.2$ ( $95 \%$ confidence interval,

\begin{tabular}{|c|c|c|c|c|c|c|c|c|c|c|c|}
\hline \multicolumn{12}{|c|}{$\begin{array}{l}\text { TABLE II } \\
\text { Evaluation of patient and control groups }(n=296)\end{array}$} \\
\hline & \multicolumn{5}{|c|}{ Patients $(n=131)$} & \multicolumn{5}{|c|}{ Controls $(n=165)$} & \multirow[b]{2}{*}{$p$} \\
\hline & $\mathrm{n}$ & $\%$ & Mean \pm SD & Median & Min-Max & $\mathrm{n}$ & $\%$ & Mean $\pm S D$ & Median & Min-Max & \\
\hline Age (year) & & & $51.8 \pm 17.1$ & 52 & $18-87$ & & & $52.9 \pm 7.1$ & 54 & $18-60$ & $0.233^{*}$ \\
\hline Sex & & & & & & & & & & & $0.577 \dagger$ \\
\hline Male & 76 & 58 & & & & 101 & 61.2 & & & & \\
\hline Female & 55 & 42 & & & & 64 & 38.8 & & & & \\
\hline $\operatorname{PLT}\left(10^{3}\right)$ & & & & 278 & $102-687$ & & & & 254 & $157-487$ & $0.002^{*}$ \\
\hline MPV & & & $8.7 \pm 1.5$ & & & & & $10.1 \pm 1.3$ & & & $<0.001 \ddagger$ \\
\hline MPV/PLT ratio & & & & 0.03 & $0.01-0.12$ & & & & 0.04 & $0.02-0.08$ & $<0.001^{*}$ \\
\hline
\end{tabular}


(a)

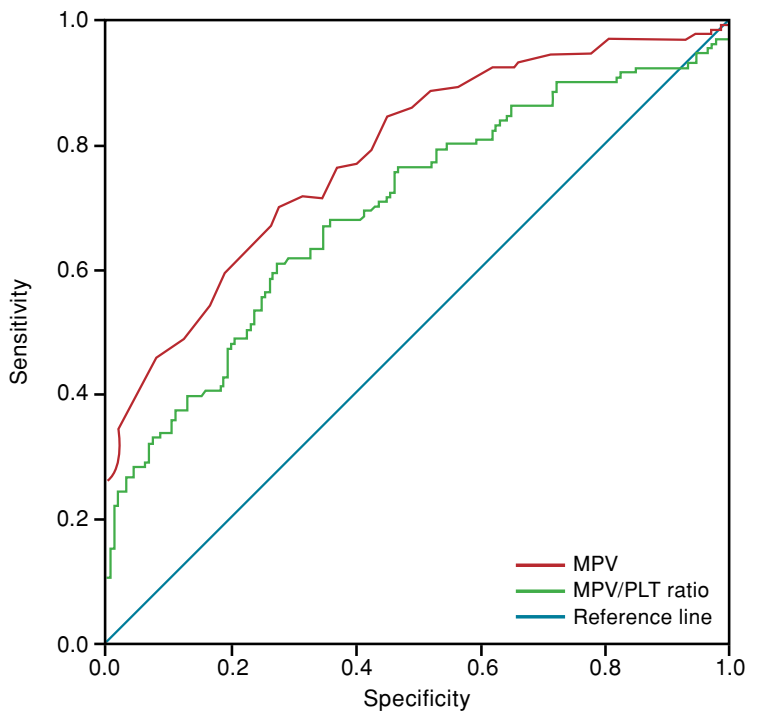

(b)

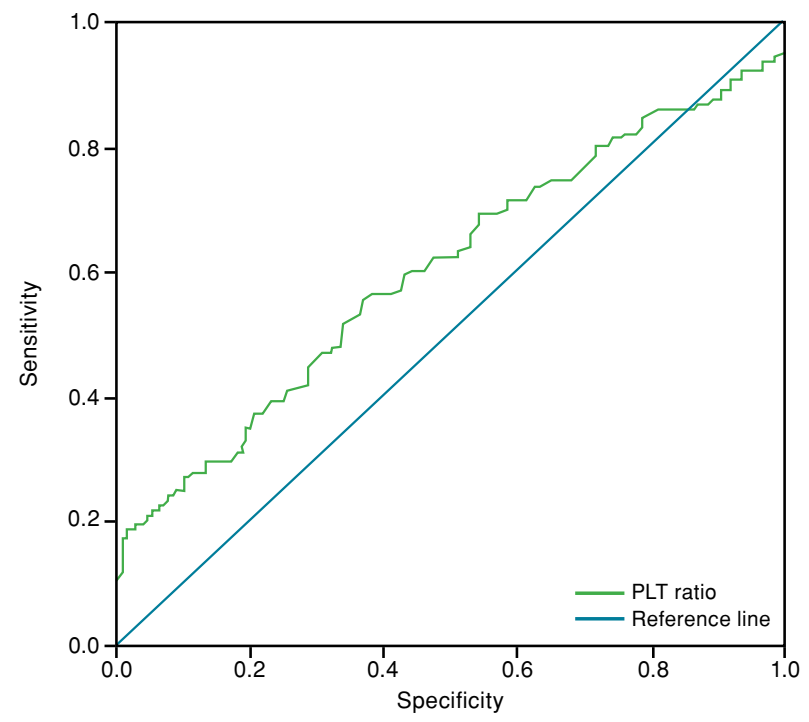

FIGURE 1. Receiver operating characteristic curves for mean platelet volume. (a) Lower results of mean platelet volume and mean platelet volume/platelet ratio indicate a more diagnostic positive test for sarcomas. (b) Higher results of platelet count indicate a more diagnostic positive test for sarcomas.

MPV: Mean platelet volume; PLT: Platelet

79.6 to 96.3$)$ months. The one-year, three-year, and five-year survival rates were $95.3 \%, 80.2 \%$, and $71.2 \%$, respectively (Figure 2). In addition, the effect of PLT count, MPV, and MPV/PLT ratio on survival was evaluated by univariate Cox regression analysis and it was found that PLT count $(\mathrm{p}=0.279)$, MPV $(\mathrm{p}=0.455)$, and MPV/PLT $(\mathrm{p}=0.271)$ ratio had no significant effect on survival.

\section{DISCUSSION}

Mean PLT volume and MPV/PLT ratio are low-cost and easily applicable methods in all patients in the preoperative routine. Our study is the first that examined the relationship between MPV and MPV/ PLT ratio and soft tissue sarcomas. ${ }^{[16]}$ The main finding of this study is that MPV and MPV/PLT ratio are lower in patients with soft tissue sarcomas compared to the healthy control group and can be used in diagnosis.

Ducimetière et al. ${ }^{[17]}$ found that $155(72 \%)$ of 214 soft tissue sarcomas were located in the lower extremity. Of these 155 cases, $88(41 \%)$ were located in the thigh. Similarly, in our study, $101(77.1 \%)$ of 131 soft tissue sarcomas were located in the lower extremity, and $64(48.9 \%)$ of them were located in the thigh. Moten et al. ${ }^{[18]}$ reported that the average age of 113 patients with extremity soft tissue sarcoma was 56.7 , and $52.2 \%$ of these patients were male. Similarly, the mean age of 131 patients in our study was $51.8 \pm 17.1$ years, and $58 \%(n=76)$ of the patients were male. Moreover, five-year survival rate in Lehnhardt et al.'s ${ }^{[19]}$ study was $70 \%$ and they reported

Stristical parameters of various diagnostic approaches for predictive value of preoperative PLT count, MPV, and MPV/PLT ratio
(n=296)




\begin{tabular}{|c|c|c|c|c|c|c|}
\hline Predictabilit & \multicolumn{5}{|c|}{ TABLE IV } & eiver \\
\hline & \multicolumn{3}{|c|}{ Mortality } & \multicolumn{3}{|c|}{ Recurrence } \\
\hline & AUC & $95 \% \mathrm{Cl}$ & $p$ & AUC & $95 \% \mathrm{Cl}$ & $p$ \\
\hline PLT & 0.595 & $0.472-0.718$ & 0.141 & 0.466 & $0.356-0.576$ & 0.545 \\
\hline MPV/PLT ratio & 0.626 & $0.503-0.748$ & 0.051 & 0.479 & $0.369-589$ & 0.711 \\
\hline MPV & 0.658 & $0.532-0.783$ & 0.014 & 0.551 & $0.437-0.665$ & 0.363 \\
\hline
\end{tabular}

the 10 -year survival rate as $45 \%$. Similarly, five-year survival rate was $71.2 \%$ in our study.

Mean PLT volume is a marker of PLT function and activation that can be determined easily during complete blood counts, with no additional cost. $^{[8]}$ Various studies have identified MPV as a useful indicator in some inflammatory diseases, and it has been associated with disease activity and severity of inflammation. Incebiyik et al. ${ }^{[20]}$ reported low MPV values in pelvic inflammatory disease, and emphasized its diagnostic value. Both basic and clinical studies have found a link between malignancy and PLT abnormalities. ${ }^{[21]}$ The consumption of PLTs at the inflammation site may be responsible for decreased MPV. Furthermore, the inflammatory environment can impair

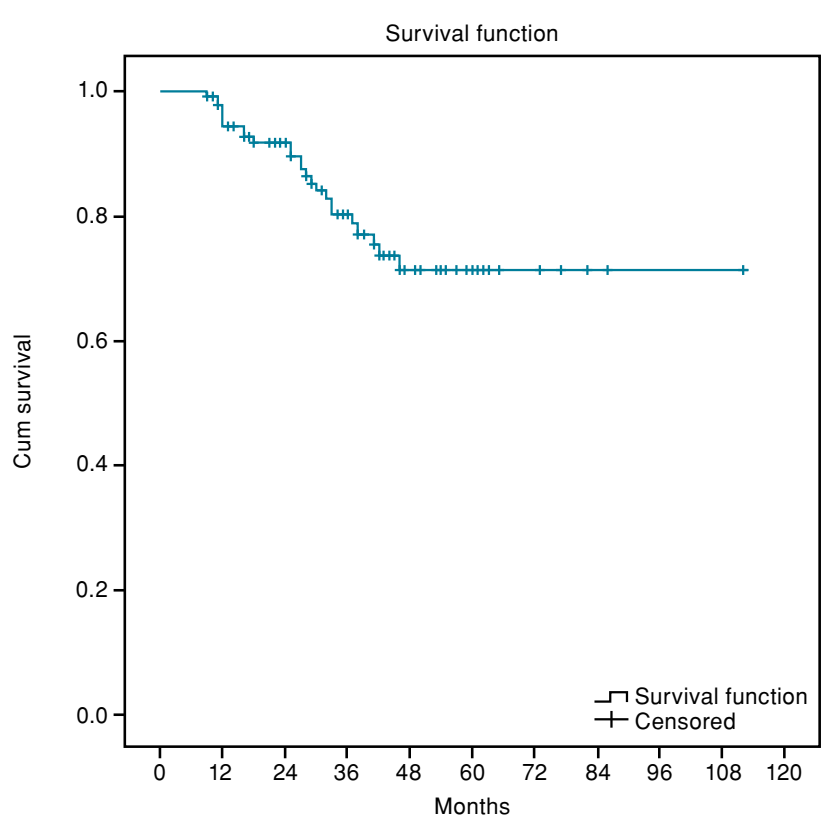

FIGURE 2. Kaplan-Meier curve for overall survival (median survival month has not been reached). megakaryopoiesis, in turn causing the release of small PLTs from the bone marrow. ${ }^{[8]}$

In recent years, studies investigating the relationship between MPV and malignancy have been increasing. Wang et al. ${ }^{[9]}$ and Yun et al. ${ }^{[10]}$ demonstrated decreased MPV and MPV/PLT ratio in bladder and renal cell cancer patients, respectively, compared to healthy individuals. Similarly, Inagaki et al. ${ }^{[11]}$ and Kumagai et al. ${ }^{[12]}$ demonstrated decreased MPV and MPV/PLT ratio in lung cancer patients. In addition, Aksoy et al. ${ }^{[13]}$ demonstrated that MPV was reduced in solid tumors that metastasized to the bone marrow. In this study, we found that MPV and MPV/PLT ratio in patients with soft tissue sarcomas were reduced compared to healthy volunteers. Therefore, we consider that MPV and MPV/PLT ratio can be used for diagnostic purposes in soft tissue sarcomas. Gastrointestinal system sarcomas can affect PLT indices by causing bleeding and anemia, while we do not expect this in extremity soft tissue sarcomas.

In this study, a relationship was found between decreased MPV and MPV/PLT ratio and soft tissue sarcomas; however, there were publications on cancers associated with increased MPV. Shen et al. ${ }^{[22]}$ demonstrated increased MPV in patients with gastric cancer. Similarly, Cho et al. ${ }^{[23]}$ demonstrated an increased MPV rate in hepatocellular cancer patients. Therefore, we think that more studies are needed to investigate the biological relationship between MPV and cancer.

There are publications that associate MPV and MPV/PLT ratio with prognosis. Shen et al. ${ }^{[22]}$ associated MPV with prognosis in gastric cancer patients. Similarly, MPV has been associated with prognosis in patients with endometrial carcinoma, cervical, ovarian, gastric, and esophageal cancer. ${ }^{[24]}$ In this study, no relationship was found between the prognosis of soft tissue sarcomas and MPV and $\mathrm{MPV} / \mathrm{PLT}$ ratio. We attribute this result to many 
other factors (treatment methods, distant organ metastases, etc.) that affect prognosis; however, we believe that studies investigating the relationship between prognosis of soft tissue sarcomas and MPV and MPV/PLT ratio are needed.

This study has some limitations. Smoking status, which may affect the MPV and MPV/PLT ratio, has not been recorded. Similarly, there is no record of drugs considered to be effective on MPV. Another limitation is that soft tissue sarcomas evaluated in this study have different biological behaviors and different treatments. Moreover, the single-center retrospective design is another limitation. Nevertheless, this study is valuable because it is the first to investigate the relationship between soft tissue sarcomas and MPV and MPV/PLT ratio.

In conclusion, MPV and MPV/PLT ratio can be used as a diagnostic support parameter in soft tissue sarcomas, but have no prognostic value. Given the low-cost and easily applicable blood parameters, more comprehensive prospective studies are needed to clarify their potential role in soft tissue sarcomas.

\section{Declaration of conflicting interests}

The authors declared no conflicts of interest with respect to the authorship and/or publication of this article.

\section{Funding}

The authors received no financial support for the research and/or authorship of this article.

\section{REFERENCES}

1. Morrison BA. Soft tissue sarcomas of the extremities. Proc (Bayl Univ Med Cent) 2003;16:285-90.

2. von Mehren M, Randall RL, Benjamin RS, Boles S, Bui MM, Casper ES, et al. Soft tissue sarcoma, version 2.2014. J Natl Compr Canc Netw 2014;12:473-83.

3. Weiss SW, Goldblum J. Enzinger and Weiss's soft tissue tumors. St. Louis: Mosby; 2001.

4. Ulucakoy C, Yapar A, Öztürk R, Toğral G, Güngör BŞ. Is there any prognostic relationship between malignant peripheral nerve sheath tumors and NF type 1? Acta Oncologica Turcica 2020;53:46-56.

5. Yapar A, Ulucaköy C, Sezgin EA, Atalay İB, Ekşioğlu MF. Diagnostic role of neutrophil-to-lymphocyte ratio and monocyte-to-lymphocyte ratio in patients with enchondroma and low-grade chondrosarcoma. Jt Dis Relat Surg 2020;31:286-90.

6. Tanriverdi O, Menekse S, Teker F, Oktay E, Nur Pilanc K, Gunaldi $\mathrm{M}$, et al. The mean platelet volume may predict the development of isolated bone metastases in patients with breast cancer: a retrospective study of the Young Researchers Committee of the Turkish Oncology Group
(TOG). J BUON 2016;21:840-50.

7. Ulucaköy C, Yapar A . Diagnostic role of NLR, MLR and PLR in patients with lipoma and liposarcoma. Turkish Journal of Clinics and Laboratory 2020;11:250-4.

8. Goubran HA, Stakiw J, Radosevic M, Burnouf T. Plateletcancer interactions. Semin Thromb Hemost 2014;40:296-305.

9. Wang X, Cui MM, Xu Y, Liu L, Niu Y, Liu T, et al. Decreased mean platelet volume predicts poor prognosis in invasive bladder cancer. Oncotarget 2017;8:68115-22.

10. Yun ZY, Zhang X, Liu YS, Liu T, Liu ZP, Wang RT, et al. Lower mean platelet volume predicts poor prognosis in renal cell carcinoma. Sci Rep 2017;7:6700.

11. Inagaki N, Kibata K, Tamaki T, Shimizu T, Nomura S. Prognostic impact of the mean platelet volume/platelet count ratio in terms of survival in advanced non-small cell lung cancer. Lung Cancer 2014;83:97-101.

12. Kumagai S, Tokuno J, Ueda Y, Marumo S, Shoji T, Nishimura $\mathrm{T}$, et al. Prognostic significance of preoperative mean platelet volume in resected non-small-cell lung cancer. Mol Clin Oncol 2015;3:197-201.

13. Aksoy S, Kilickap S, Hayran M, Harputluoglu H, Koca E, Dede DS, et al. Platelet size has diagnostic predictive value for bone marrow metastasis in patients with solid tumors. Int J Lab Hematol 2008;30:214-9.

14. Obuchowski NA. Receiver operating characteristic curves and their use in radiology. Radiology 2003;229:3-8.

15. Metz CE. Basic principles of ROC analysis. Semin Nucl Med 1978;8:283-98.

16. Atik OŞ. Is there something new and interesting in my article? Eklem Hastalik Cerrahisi 2019;30:69.

17. Ducimetière F, Lurkin $A$, Ranchère-Vince $D$, Decouvelaere $\mathrm{AV}$, Péoc'h $\mathrm{M}$, Istier $\mathrm{L}$, et al. Incidence of sarcoma histotypes and molecular subtypes in a prospective epidemiological study with central pathology review and molecular testing. PLoS One 2011;6:e20294.

18. Moten AS, Zhao H, Howell K, Nadler A, Reddy SS, von Mehren M, et al. Soft tissue sarcoma of the extremity: Characterizing symptom duration and outcomes. Surg Oncol 2019;29:190-5.

19. Lehnhardt M, Hirche C, Daigeler A, Goertz O, Ring A, Hirsch T, et al. Soft tissue sarcoma of the upper extremities. Analysis of factors relevant for prognosis in 160 patients. Chirurg 2012;83:143-52.

20. Incebiyik A, Seker A, Vural M, Gul Hilali N, Camuzcuoglu A, Camuzcuoglu H. May mean platelet volume levels be a predictor in the diagnosis of pelvic inflammatory disease? Wien Klin Wochenschr 2014;126:422-6.

21. Sierko E, Wojtukiewicz MZ. Platelets and angiogenesis in malignancy. Semin Thromb Hemost 2004;30:95-108.

22. Shen XM, Xia YY, Lian L, Zhou C, Li XL, Han SG, et al. Mean platelet volume provides beneficial diagnostic and prognostic information for patients with resectable gastric cancer. Oncol Lett 2016;12:2501-6.

23. Cho SY, Yang JJ, You E, Kim BH, Shim J, Lee HJ, et al. Mean platelet volume/platelet count ratio in hepatocellular carcinoma. Platelets 2013;24:375-7.

24. Erpenbeck L, Schön MP. Deadly allies: the fatal interplay between platelets and metastasizing cancer cells. Blood 2010;115:3427-36. 